\title{
The Set Point of Intact Parathyroid Hormone-Ionized Calcium Curve during the Progression of Secondary Hyperparathyroidism among Patients Undergoing Haemodialysis
}

\author{
T Sudhakar ${ }^{1}$, Sabitha Kandi ${ }^{2}$, B venugopal ${ }^{2}$, K. Bhagwan Reddy ${ }^{3}$, K. V. Ramana ${ }^{3, *}$ \\ ${ }^{1}$ Department of Biochemistry, HOD lab in-charge, Apollo Reach Hospital, Karimnagar, Andhra Pradesh \\ ${ }^{2}$ Department of Biochemistry, Chalmeda Anadrao Institute of Medical Sciences, Karimnagar \\ ${ }^{3}$ Department of Biochemistry, Prathima Institute of Medical Sciences, Karimnagar \\ *Corresponding author: ramana_20021@rediffmail.com
}

Received August 04, 2014; Revised August 15, 2014; Accepted August 19, 2014

\begin{abstract}
The parathyroid gland secretes parathyroid hormone (PTH) which is a key element in the regulation of serum calcium. The PTH elevates serum calcium activities by regulating its action on the bones, kidneys and small intestine. The set point of PTH secretion defines the sensitivity of the parathyroid glands to calcium concentration. Secondary hyperparathyroidism (SHPT) is a common complication of end stage renal disease (ESRD). Ionized calcium is physiologically active form of calcium status of the body and is used for accurately monitoring calcium status in renal diseases. The present study states that the ionized calcium is the set point of secondary hyperparathyroidism undergoing haemodialysis and the range of set point lies between $2.3-4.8 \mathrm{mg} / \mathrm{dl}(0.57-1.2$ $\mathrm{mmol} / \mathrm{L}$ ). The status of $\mathrm{iPTH}$, set point are frequently monitored in subtotal hyperparathyroidectomy where imaging studies are not beneficial (anatomically situated on postero-lateral surface of thyroid gland) to know the appearance of parathyroid gland.
\end{abstract}

Keywords: set point, ionized calcium, Secondary hyperparathyroidism (SHPT), haemodialysis

Cite This Article: T Sudhakar1, Sabitha Kandi, B venugopal, K. Bhagwan Reddy, and K. V. Ramana, "The Set Point of Intact Parathyroid Hormone-Ionized Calcium Curve during the Progression of Secondary Hyperparathyroidism among Patients Undergoing Haemodialysis.” American Journal of Medical and Biological Research, vol. 2, no. 4 (2014): 87-90. doi: 10.12691/ajmbr-2-4-1.

\section{Introduction}

The parathyroid gland plays a central role in controlling serum calcium concentrations by regulating secretion of parathyroid hormone $(\mathrm{PTH})$. The PTH elevates serum calcium levels via its effect on the bones, kidneys and small intestine. The increased or decreased secretions of PTH are dependent on the levels of serum calcium $[1,2]$. Secondary hyperparathyroidism (SHPT) is a common complication of end stage renal disease (ESRD). The decrease in functioning renal mass results in hypocalcaemia, hyperphosphatemia and reduced calcitriol levels which stimulate PTH secretion leading to hyperplasia of the parathyroid gland [3]. The extracellular ionized calcium regulates the secretion of $\mathrm{PTH}$, which interacts through calcium sensing receptors on parathyroid cell $[4,5]$. Thus, in hyperparathyroidism either primary or secondary or pseudo or idiopathic there is decreased calcium receptors $[6,7,8,9]$. Physiologically, the relation between PTH secretion and calcium concentration is defined by a sigmoid curve [10].

The set point of PTH secretion is defined as the concentration of calcium required to reduce maximum
PTH secretion by $50 \%$ [11,12], or it can also be defined as the serum calcium concentration required to reduce PTH secretion to half the difference between the maximum and minimum levels $[13,14]$. The set point of PTH secretion defines the sensitivity of the parathyroid glands to calcium concentration [15]. Ionized Calcium is normally better for accurately monitoring calcium status in renal diseases $[16,17]$. The advantages of measuring ionized calcium over total calcium are: [18]

a) There is no effect of venous occlusion or change of posture on the ionized calcium

b) More reliable indicator of calcium status of patients in certain clinical conditions

c) Physiologically active form of calcium(50\% of total calcium)

The measurement of ionized calcium was used to done by calculation method, but by the measurement of ionized calcium by ion-selective electrode (ISE) technology, the errors are less and this method gives accurate and precise values. The sample drawn for analysis of ionized calcium should be without anticoagulant, without air bubbles. The use of anticoagulants like heparin for measuring ionized calcium decreases the concentration of ionized calcium in the sample [19]. 
The aim of the present study is to determine the set point of intact parathyroid hormone - ionized calcium curve during the progression of SHPT in patients of haemodialysis.

\section{Materials and Methods}

50 samples of blood from haemodialysis patients with SHPT attending Nephrology OP in a multi-specialty Hospital, Karimnagar, Telangana and 11 healthy control samples were also collected. The samples were processed for iPTH, total calcium and ionized calcium.

\subsection{Blood Sample Collection}

The samples were collected in fasting conditions under aseptic procedure. An Informed consent was obtained from the subjects involved in the study. $5 \mathrm{ml}$ blood sample without any addition of anticoagulant was collected and allowed to clot, and then centrifuged at $3000 \mathrm{rpm}$ for 20 minutes. The serum obtained is used for the analysis.

\subsection{Exclusion Criteria}

- Hormonal Imbalance

- Diabetes mellitus

- Liver disease

- Vitamin D deficiency

\subsection{Inclusion Criteria}

* Chronic Kidney Disease.

Intact PTH assay - Done by Chemiluminiscence method in Abortt Chemiluminiscence Analyzer (Architect)

Total calcium - Done by O-Crespthalene Complexone method

Ionized Calcium - Done by calculation ISE procedure

\section{Results}

The mean and SD values of patient group of iPTH are 321.8102 and 225.9290 and control group are 49.35 and 15.45 with $\mathrm{p}$ value 0.0001 extremely significant. The mean and SD values of ionized calcium are 3.8410 and 0.5255 and control group are 4.34 and 0.28 with p value 0.001 statistically significant (Table 1 ).

The mean difference between total calcium and iPTH are 314.1792 and $95 \%$ confidence interval of this difference is from the range of 377.5877 to 250.7707 . Similarly, the mean difference between ionized calcium and iPTH are 161.3970 with 95\% confidence interval of this difference ranging from 193.9148 to 128.8792 (Table 1) (Figure 1).

Table 1. The statistical data of iPTH, Total calcium and ionized calcium

\begin{tabular}{|c|c|c|c|}
\hline Parameter & \multicolumn{2}{|c|}{ Mean +/- SD } & P value \\
\hline & Control & Patient & \\
\hline Intact PTH & $49.35+/-15.45$ & $321.81+/-225.9$ & $0.001^{*}$ \\
\hline Total Calcium & $8.68+/-0.56$ & $7.63+/-1.24$ & $0.001^{*}$ \\
\hline Ionised Calcium & $4.34+/-0.28$ & $3.84+/-0.52$ & $0.001^{*}$ \\
\hline
\end{tabular}

The statistical analysis was done using Graph pad prism software.

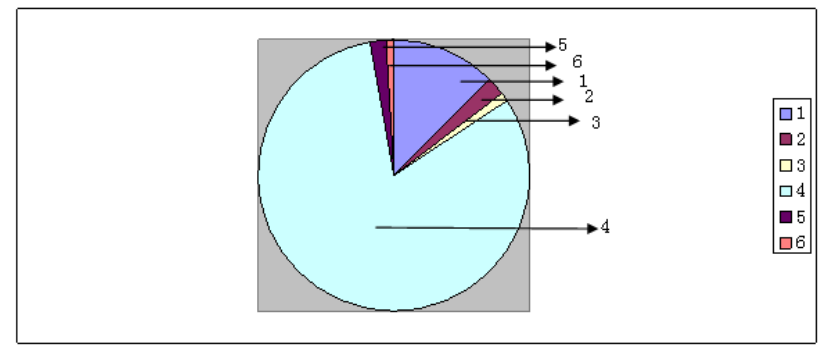

Figure 1. The pie diagram of intact PTH, Total Calcium and Ionized calcium of Patients and control group

1- Intact PTH control group.

2- Total calcium control group.

3- Ionised calcium control group.

4- Intact PTH of patient group.

5- Ionised calcium patient group.

6- Total calcium patient group.

The set point of intact PTH - Ionized calcium curve among SHPT patients undergoing hemodialysis (shown in graph). From the graph it is concluded that the set point in this study lies in the range of 2.3 to $4.8 \mathrm{mg} / \mathrm{dl}(0.57-1.2$ $\mathrm{mmol} / \mathrm{L})$.

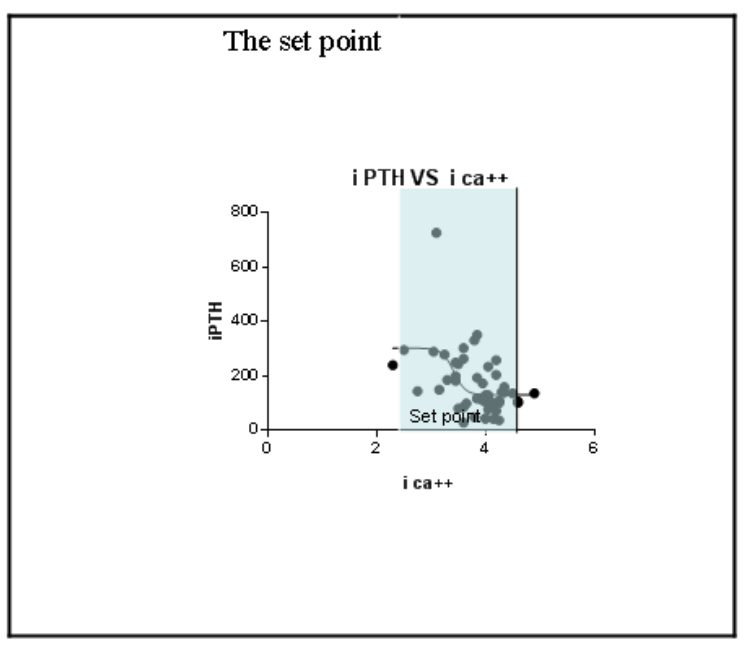

Graph. The set point of SHPT among hemodialysis (shown in colored region)

\section{Discussion}

The results of our study indicate that the ionized calcium is the set point for the patients undergoing haemodialysis with chronic kidney disease and the range of this set point lies between $2.3-4.8 \mathrm{mg} / \mathrm{dl}(0.57-1.2$ $\mathrm{mmol} / \mathrm{L})$. The influence of SHPT on the set point of the $\mathrm{PTH}$ - calcium curve is controversial. The in-vitro experiments showed an increased set point in SHPT (20) however clinical studies with haemodialysis patients provided a variety of results. Ramirez et. al.,. and Goodman et al., reported no change in the set point with SHPT [21,22]. Malberti et al. and Goodman et al. found no change in set point of patients with moderate SHPT but described an increase in set point in patients with severe SHPT [23,24] contrast to this Borrego et al. and Cardinal et al. observed a decrease in set point in uremic patients $[25,26]$. The decrease in calcium receptors (CR) with primary hyperparathyroidism correlated with the increase 
in the set point [27] but the reduction in CR occurs in the course of SHPT. A decrease in vitamin D receptor (VDR), reduces the ability of calcitriol to inhibit parathyroid gland proliferation is an important etiopathogenic factor in both primary and secondary hyperparathyroidism [28,29]. There were some studies which states that the set point of the PTH- calcium curve changes with variation in extracellular calcium i.e., decreases with hypocalcaemia and increases with hypercalcaemia [30,31,32,33].

In a study conducted to know the difference between set point in-vivo and in-vitro it is concluded that the set point invivo calcium is more related to the serum calcium concentration than the base line (level of PTH before hypo or hypercalcaemia) PTH concentration [10]. In clinical studies on dialysis patients showed no correlation between set point of PTH secretion and magnitude of hyperparathyroidism, but in-vitro studies in dialysis patients with SHPT on removal of parathyroid gland hypercalcaemia was demonstrated which caused an increase in set point of PTH stimulated by calcium, suggesting intrinsic abnormality of hyper plastic parathyroid cell [34].

\section{Conclusion}

The set point defines the sensitivity of parathyroid gland to calcium concentration, the present study states that the ionized calcium is the set point of secondary hyperparathyroidism undergoing haemodialysis and the range of set point lies between $2.3-4.8 \mathrm{mg} / \mathrm{dl}(0.57-1.2$ $\mathrm{mmol} / \mathrm{L}$ ). The levels of intact $\mathrm{PTH}$, set point is frequently monitored in subtotal hyperparathyroidectomy where imaging studies are not beneficial (anatomical position postero-lateral to thyroid gland) to know the size of parathyroid gland. It highlights the significance of measuring iPTH and ionized calcium activities among haemodialysis patients in the diagnosis of hyperparathyroidism.

\section{Reference}

[1] Brown EM. Extracellular $\mathrm{ca}^{2}{ }^{2}$ sensing, regulation of parathyroid cell function, and role of $\mathrm{ca}^{+}{ }^{2}$ and other ions as extracellular (first) messengers. Physiol Rev. 1991: 71; 371-411.

[2] Brown EM and Macleod RJ. Extracellular calcium sensing and extracellular calcium signaling. Physiol Rev. 2001:81; 239-297.

[3] Silver J, Kilav R \& Naveh-Many T. Mechanisms of secondary hyperparathyroidism. American Journal of Physiology. 2002: 23: F367-F376.

[4] Brown EM, Gamba G, Riccardi D et al. Cloning and characterization of an extracellular $\mathrm{ca}^{2}{ }^{2}$-sensing receptor from bovine parathyroid. Nature. 1993: 366: 575-80. [pub med]

[5] Chattopadhyay N, Mothal A, Brown EM. The calcium-sensing receptor: Window into the physiology and pathophysiology of mineral ion metabolism. Endocr Rev. 1996; 17: 289-307.

[6] Saidak Z, Mentaverri R, Brown EM. The role of the calciumsensing receptor in the development and progression of cancer. Endocr Rev. 2009; 30: 178-95. [pub med]

[7] Kifor O, Moore FD Jr, Wang P, Goldstein M, Vassilev P et al.,. Reduced immunostaining for the extracellular $\mathrm{Ca}^{2}{ }^{2}$ sensing receptor in primary and uremic secondary hyperparathyroidism. J Clin Endocrinol Metab. 1996;81: 1598-1606. [pub med]

[8] Gogusev J, Duchambon P, Hory B, Giovannini M, Goureau Y et al.,. Depressed expression of calcium receptor in parathyroid gland tissue of patients with hyperparathyroidism. Kidney Int. 1997; 51: 328-36. [pub med]
[9] Mathias RS, Nguyen HT, Zhang MY, Portole AA. Reduced expression of the renal calcium-sensing receptor in rats with experimental chronic renal insufficiency. J Am Soc Nephrol. 1998; 9: 2067-74. [pub med]

[10] C.E.Duran, Jose Vicente Torregrosa, Y. ALmaden, A. Canalejo, J. M.Campistol et al.,. Dynamics of calcium-regulated PTH secretion in secondary hyperparathyroidism: comparison between invivo Vs invitro responses. Nefrologia 2010; 30 (1); 73-77.

[11] Felsenfeld AJ, Llach F. Parathyroid gland function in chronic renal failure. Kidney Int 1993; 43: 771-89. [pub med]

[12] Felsenfeld AJ, Rodriguez M. The set point of calcium. Another view. Nephrol Dial Transplant. 1996;11: 1722-5.[pub med]

[13] Goodman W, Salusky IB. Parathyroid gland function and the set point for PTH release: understanding the available data. Nephrol Dial Transplant. 1996:11: 16-8. [pub med]

[14] Parofitt AM. Relation between parathyroid cell mass and plasma calcium concentration in normal and uremic subjects. Arch Intern Med. 1969; 124: 269-73. [pub med]

[15] Felsenfeld AJ, Rodriguez M, Aguilera-Tejero E. Dynamics of parathyroid hormone secretion in Health and secondary hyperparathyroidism. Clin J Am Soc Nephrol. 2007: 2: 1283-305. [pub med]

[16] Buritt MF, Picrides AM. Comparative studies of total and ionized calcium in serum in normal subjects and patients with renal disorders. Mayo Clin Prac 1980; 55: 606-13.

[17] Gidenne S, Vigezzi JF, Delacour H, Damiano J, Clerc Y. Direct determination or estimated value of plasma ionized calcium: indications and limits. Ann Biol Clin (Paris). 2003: 61 (4): 393-9.

[18] Robertson WG. Measuremenr of ionized calcium in body fluids-a review. Ann Clin Biochem. 1976; 13 (6): 540-8.

[19] Soong WJ, Wang HZ, Hwang B. Heparinization of blood decreases ionized calcium concentration. Zhonghua Yi Xue Za Zhi (Taipei). 1991; 47 (5): 331-5.

[20] Brown EM, Wilkson RE, Eastman RC, Pallota J \& Marynick SP. Abnormal regulation of parathyroid hormone release by calcium in secondary hyperparathyroidism due to chronic renal failure. Journal of Clinical Endocrinology and Metabolism. 1993; 76: 1489-94.

[21] Ramirez JA, Goodman WG, Gornbein J, Menezes C, Moulton L et al.,. Direct invivo comparison of calcium-regulated parathyroid hormone secretion in normal volunteers and patients with secondary hyperparathyroidism. Journal of clinical Endocrinology and Metabolism. 1993; 76: 1489-94.

[22] Goodman WG, Belin T, Gales B, Juppner H, Segre GV et al., Calcium regulated parathyroid hormone release in patients with mild or advanced secondary hyperparathyroidism. Kidney International. 1995; 48: 1553-1558.

[23] Malberti F, Corradi B, Pagliari, Romanini D, Gazo A, et al.,. The sigmoidal parathyroid hormone-ionized calcium curve and the set point of calcium in hemodialysis and continuous ambulatory peritoneal dialysis. Peritoneal Dialysis International. 1993; 13: (suppl 2): S476-S479.

[24] Goodman WG, Veldhuis JD, Belin TR, Van Herle AJ, Juppner H at al.,. Calcium sensing by parathyroid glands in secondary hyperparathyroidism. Journal of clinical Endocrinology \& Metabolism. 1998: 83: 2765-72.

[25] Borrego MJ, Felsenfeld AJ, Martin-Malo A, Almaden Y, Concepcion MT et al.,. Evidence for adaptation of the entire PTHcalcium curve to sustained changes in the serum calcium in hemodialysis patients. Nephrology Dialysis and Transplantation. 1997; 12: 505-513.

[26] Cardinal H, Brossard JH, Roy L, Lepage R, Rousseau L \& D'Amour P. the setpoint of parathyroid hormone stimulation by calcium is normal in progressive renal failure. Journal of clinical Endocrinology and Metabolism. 1998; 83: 3839-3844.

[27] Ritter CS, Finch JL, Slatopolsky EA \& Brown AJ. Parathyroid hyperplasia in uremic rats precedes down-regulation of the calcium receptor. Kidney International. 2001; 60: 1737-44.

[28] Carling T, Rastad J, Szabo E, Westin G \& Akerstrom G. Reduced parathyroid vitamin $\mathrm{D}$ receptor messenger ribonucleic acid levels in primary and secondary hyperparathyroidism. Journal of Clinical Endocrinology and Metabolism. 2000; 85: 2000-2003.

[29] Lewin E, Garfia B, Recio FL, Rodriguez M \& Olgaard K. Persistent downregulation of calcium-sensing receptor mRNA in rat parathyroids when severe secondary hyperparathyroidism is reversed by isogenic kidney transplantation. Journal of the American Society of Nephrology. 2002; 13: 2110-2116. 
[30] Pahl M, Jara A, Bover J, Rodriguez M \& Felsenfeld AJ. The set point of calcium and the reduction of parathyroid hormone in hemodialysis patients. Kidney Interrnational. 1996; 49: 226-231.

[31] Rodriguez M, Caravaca F, Fernandez E, Borrego MJ, Lorenzo V et al.,. Evidence for both abnormal set point of PTH stimulation by calcium and adaptation to serum calcium in hemodialysis patients with hyperparathyroidism. Journal of bone and mineral research. 1997: 12: 347-355.

[32] Hardy-Yverneau P, Shenouda M, Moriniere P, Lagallais C, Brazier $\mathrm{M}$ et al.,. The dependency of calcium set point on basal plasma calcium in dialysis patients: a better explanation for the discrepancies regarding its link with PTH secretion than methodological differences. Clinical Nephrology. 1998; 50: 236246.

[33] Malberti F, Farina M \& Imbasciati E. The PTH-Calcium curve and the set point of calcium in primary and secondary hyperparathyroidism. Nephrology Dialysis and Transplantation. 1999; 14: 2398-2406.

[34] Rodriguez M, Caravaca F, Fernandez E, Borrego MJ, Lorenzo V et al. Evidence for both abnormal set point of PTH stimulation by calcium and adaptation to serum calcium in hemodialysis patients with hyperparathyroidism. Journal of Bone and Mineral Research. 1997:12:347-355. 